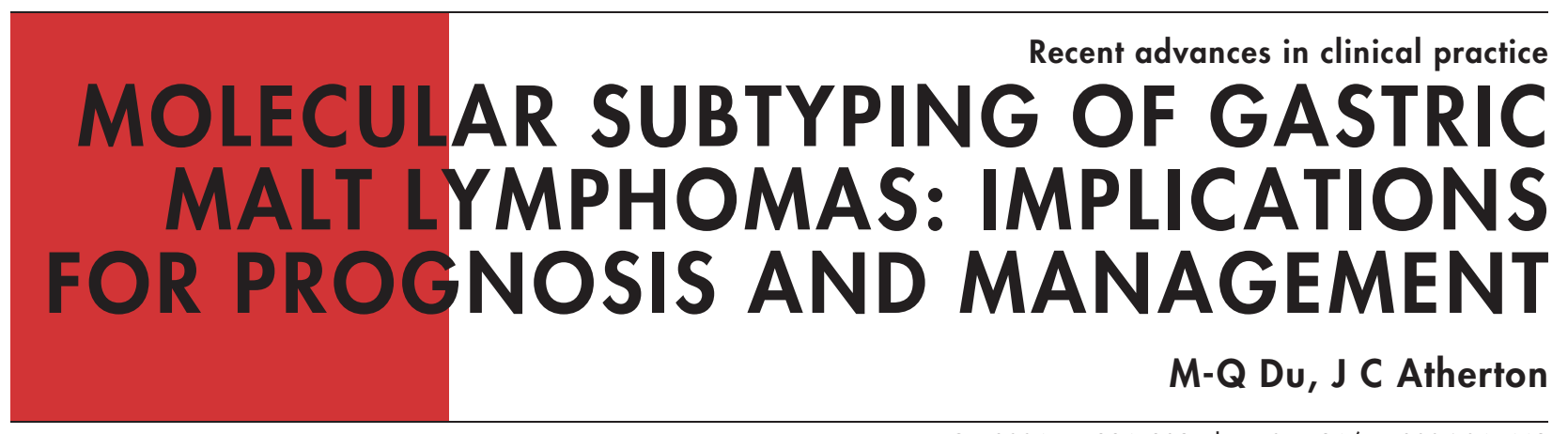

Gut 2006;55:886-893. doi: 10.1136/gut.2004.061663

S ince mucosa associated lymphoid tissue (MALT) lymphomas were first recognised as a distinct entity in 1983, their characterisation and management have seen a series of rapid advances. Here we concentrate on MALT lymphomas at the commonest site-the stomach. Historically, despite their indolence, "localised" gastric low grade lymphomas were treated with surgery, and chemotherapy or radiotherapy were reserved for systemic spread. This emphasis has gradually changed but the major advance came with the discovery that these tumours were caused by Helicobacter pylori infection, and the remarkable finding that most resolved with its treatment. ${ }^{1} H$ pylori eradication quickly became a firstline therapy, and the research focus changed to how best to assess which cases would respond to this. Endoscopic ultrasound became important for staging and, to some extent, stage predicted response to $H$ pylori eradication. However, the most exciting research over the past eight years has been in understanding the molecular genetics of these fascinating tumours. In this review, we describe these advances and discuss their implications for management, particularly the extent to which they predict the biological behaviour and response of the tumour to $H$ pylori treatment.

\title{
CLASSIFICATION AND PATHOLOGY
}

The term MALT lymphoma was first suggested by Isaacson and Wright in 1983 to describe low grade gastric B cell lymphoma and immunoproliferative small intestinal disease. ${ }^{2}$ It was soon extended to include similar lymphomas at other mucosal sites such as the lung, occula adnexa, thyroid, and salivary glands. Later the World Health Organisation renamed these tumours "Extranodal marginal zone B cell lymphomas of mucosa associated lymphoid tissue" but also retained the shortened term "MALT lymphoma". ${ }^{3}$ The stomach is by far the commonest site for MALT lymphomas, comprising $70 \%$ of the total. Despite this, gastric MALT lymphoma is an unusual disease, with an incidence of approximately 0.8 per 100000 per year. This sounds low but the tumour is not uncommonly seen by gastroenterologists-approximately $5 \%$ of gastric tumours are lymphomas and about half of these are low grade MALT lymphomas.

Histologically, a low grade gastric MALT lymphoma appears as a diffuse spread of neoplastic cells from the marginal zone of lymphoid follicles. There is considerable heterogeneity in the tumour cells themselves between cases, and also frequently within a case. The most important diagnostic feature is the presence of lymphoepithelial lesions, where epithelial structures are invaded by neoplastic cells. Histological diagnosis can be difficult, particularly where lymphoid follicles are surrounded by diffusely infiltrating small lymphocytes or marginal zone cells but there are no prominent lymphoepithelial lesions (grade 3 or 4 cases). ${ }^{4}$ B cell lymphomas can potentially be diagnosed by showing they are clonal on the basis of all cells having the same immunoglobulin gene rearrangement, but this has proven difficult in the stomach as polymerase chain reaction (PCR) based tests show apparent clonality of B cells even in simple chronic gastritis. However, an article in this issue of $G u t^{5}$ describes a robust PCR based method which suggests that only lymphomas are truly clonal (see page 782). Results of clonality testing on chronic gastritis seem to have been falsely positive due to limitations in previous methodology. This appears to provide a practical way forward in working towards more definitive diagnosis in difficult cases.

See end of article for authors' affiliations

Correspondence to: Professor J C Atherton, Wolfson Digestive Diseases Centre, University Hospital, Nottingham NG7 2UH, UK; john.atherton@

nottingham.ac.uk

\section{NATURAL HISTORY}

\section{Dissemination}

An important point for consideration of optimal management strategies, which is not immediately clear from initial histopathological assessment, is that both local and systemic dissemination are very common. By careful histological examination of gastrectomy specimens, Wotherspoon et al showed that numerous small tumour foci, identical to the main MALT lymphoma mass as assessed by immunoglobulin (Ig) light chain restriction, were distributed throughout the gastric mucosa, including in macroscopically normal regions. ${ }^{6}$ Subsequent studies using microdissection and PCR analysis of the rearranged Ig genes confirmed the clonal identity 
of these multiple tumour foci and also showed that tumour cells were frequently present in reactive lymphoid components that showed no histological evidence of lymphoma. ${ }^{7}$ This widespread intramucosal dissemination of gastric MALT lymphoma appears to be an early event: studies have confirmed that it is common, even in lymphomas thought by imaging studies to be very localised. ${ }^{8}$

Regional lymph nodes are frequently involved in gastric MALT lymphoma, such involvement occurring in at least $40 \%$ of cases. ${ }^{9}{ }^{10}$ Spread to more distant sites also occurs, especially to other mucosal sites such as the small intestine, colon, salivary gland, and splenic marginal zone. ${ }^{11}{ }^{12}$ Peripheral lymph nodes are rarely involved but bone marrow involvement is seen in approximately $10 \%$ of cases. ${ }^{13}$ The propensity of gastric MALT lymphoma to disseminate to other mucosal sites and to the splenic marginal zone is believed partially to reflect the homing properties of the tumour cells. ${ }^{14}$

The unusual dissemination pattern of gastric MALT lymphoma has significant implications for its clinical management. Firstly, clinical staging should concentrate on sites where the tumour cells tend to spread. ${ }^{15}$ Secondly, surgery is illogical as a curative procedure, as even where macroscopic spread cannot be identified microscopic spread is likely.

\section{High grade transformation}

Approximately $60 \%$ of gastric lymphomas are high grade, and these are termed diffuse large B cell lymphomas (DLBCL). ${ }^{16}$ The extent to which DLBCL arise de novo in the stomach and the extent to which they transform from low grade MALT lymphomas is unclear, but such transformation does occur. Lymphomas with small and large cell components are well described, and these components are usually clonal. ${ }^{17-19}$ Thus an important aim in treating low grade MALT lymphomas is to prevent transformation to DLBCL, and an important question for molecular testing is the extent to which it can predict the risk of high grade transformation.

\section{Prognosis}

When considering treatment of low grade gastric MALT lymphoma, it is important to recognise the indolence of the disease. Despite its ability to spread or transform, most cases remain localised within the stomach for many years. Ten year survival for gastric MALT lymphoma is $90 \%$, compared with $45 \%$ for DLBCL, ${ }^{13}{ }^{20}$ further emphasising the desirability of predicting the biological behaviour of individual tumours.

\section{HELICOBACTER PYLORI AND GASTRIC MALT LYMPHOMA}

There is now compelling evidence that gastric MALT lymphoma is caused by infection with $H$ pylori. This bacterial infection not only triggers the acquisition of MALT in the gastric mucosa, a prerequisite for lymphoma development, ${ }^{21}{ }^{22}$ but also plays a critical role in malignant transformation and subsequent clonal expansion of the transformed cells. In vitro, the growth of lymphoma cells is stimulated by heat killed $H$ pylori, ${ }^{23-25}$ and in vivo, eradication of the organism results in complete regression of the lymphoma in the majority of cases. ${ }^{126}$

Approximately, 5-10\% of gastric MALT lymphomas appear not to be associated with $H$ pylori, and the aetiological factor in these cases remains unclear. Some cases may be explained by undiagnosed $H$ pylori infection, and cases where $H$ pylori serology is positive but biopsy based tests are negative are not uncommon. This may be because some lymphomas arise in atrophic stomachs where $H$ pylori bacterial load is low. Other cases may be associated with $H$ heilmannii or other zoonotic gastric Helicobacters, ${ }^{27}$ and the pathogenic role of these in gastric MALT lymphoma development is thought to be similar to that of $H$ pylori. In support of this, gastric MALT lymphomas associated with $H$ heilmannii infection have been shown to respond to antibiotic therapy. ${ }^{27}$

\section{TREATMENT}

Careful staging, including endoscopic ultrasound, is needed before treatment. To some extent this can predict the chances of $H$ pylori treatment leading to lymphoma regression but eradication of $H$ pylori is indicated in all cases of MALT lymphoma in which it is found.

\section{Helicobacter pylori eradication as firstline treatment}

Approximately $70 \%$ of cases of low grade gastric MALT lymphoma are successfully treated by $H$ pylori eradication. In about $50 \%$ of the responsive cases, monoclonal cells become completely undetectable, but in the other $50 \%$, although the histology returns to normal, molecular testing shows persistence of some monoclonal cells. It remains unclear whether this "minimal residual disease" represents persistent tumour cells or merely a population of memory B cells with no malignant potential. ${ }^{28}$ So far, follow up series have been reassuring, implying that the presence of minimum residual disease is clinically unimportant and that this state represents a cure..$^{29}{ }^{30}$ However, there are isolated reports of relapse, and very long term follow up of at least a cohort of treated patients is needed for complete reassurance.

Because of the close association between gastric MALT lymphoma and $H$ pylori, the infection should be rigorously sought, and initial negative tests should prompt reinvestigation. Modalities include biopsy urease test, histology (from parts of the stomach not affected by lymphoma), culture, and urea breath test. Serology alone should not be used as some kits are unreliable and it does not necessarily imply current infection. However, occasionally other tests are consistently negative in MALT lymphoma and serology is consistently positive, and in this situation, unless the patient has had recent specific $H$ pylori treatment, we feel treatment is indicated.

Effective $H$ pylori treatment is important to achieve an early response and avoid emergence of antibiotic resistant strains which can be hard to eradicate. Antibiotic resistance is very common after a course of failed treatment and is irreversible. The two main causes of treatment failure are antibiotic resistance and lack of full compliance with treatment. A full antibiotic history should thus be taken and antibiotics previously used for other infections avoided. The patient should be told of the importance of full compliance, warned of minor side effects, given instructions to complete treatment regardless, and if possible given written instructions and a contact number to call in case of problems. We consider it desirable to culture $H$ pylori before treatment in the setting of MALT lymphoma and give antibiotics guided by known sensitivities, but this is not common practice. Short of this, the best recognised regimens are triple therapy with full dose proton pump inhibitor twice daily, clarithromycin $500 \mathrm{mg}$ twice daily, and either amoxicillin $1 \mathrm{~g}$ twice daily or metronidazole $400 \mathrm{mg}$ twice daily. ${ }^{31}$ Although one week of treatment has been shown to be effective in northern 
European trials, meta-analysis shows that two weeks gives better eradication rates worldwide. ${ }^{32}$

One month after treatment of $H$ pylori, success can be checked by the non-invasive urea breath test. For this, patients must have been off proton pump inhibitors for at least two weeks. Follow up endoscopies needed later to assess the response of the tumour give the opportunity to double check on $H$ pylori treatment success.

\section{Follow up of gastric MALT lymphoma after $H$ pylori treatment}

There are no universally agreed protocols for follow up after H pylori treatment. Some authorities advocate three monthly follow up, ${ }^{33}$ and some six monthly ${ }^{34}{ }^{35}$ until regression is achieved, which is usually within one year, but rarely may take up to two or three. ${ }^{36} 33$ Endoscopic ultrasound is increasingly being used in follow up as an adjunct to endoscopy and biopsy. ${ }^{37}$ Lack of response or stable disease at one year is usually considered an indication for radiotherapy or chemotherapy. Where $H$ pylori treatment leads to complete regression, relapse occurs in less than $10 \%$ of cases, and given the indolence of the disease the necessity for continued follow up is debateable, especially in the elderly. Despite this, because some patients do relapse, even after many years, most authorities advise continuing follow up on a yearly basis. ${ }^{35} 3839$ Prediction of which patients will and will not respond to $H$ pylori treatment would aid rational design of follow up protocols and early decision making about whether radiotherapy or chemotherapy are needed.

\section{Role of chemotherapy, radiotherapy, and surgery}

Chemotherapy and radiotherapy are reserved for cases which do not respond to $H$ pylori eradication. MALT lymphomas respond well to both of these modalities but they have not been subjected to rigorous comparative studies. Single agent chemotherapy (with cyclophosphamide, chlorambucil, or even ritumimab) or low dose radiotherapy gives a five year disease free survival of $50-80 \%$, varying in different reports. $^{35-40}$ Both of these modalities preserve gastric function. In contrast, although local surgical resection gives excellent five year survival, it is now recognised that the disease is often detectable throughout the stomach or more distantly using molecular tests of clonality. Thus surgery

\section{H pylori and MALT lymphomas}

- MALT lymphomas may spread and cause local complications.

- MALT lymphomas (low grade) may transform into diffuse large B cell lymphomas (high grade).

- Gastric MALT lymphoma cells are widespread in the mucosa, even when the lymphoma appears localised on conventional staging.

- This means that local treatment such as limited resection is illogical except for management of complications.

- $H$ pylori treatment leads to gastric MALT lymphoma regression in approximately $70 \%$ of cases.

- Up to $50 \%$ of responsive cases still have "minimal residual disease" and although it appears this has no residual malignant potential, further and longer follow up studies are needed.

- Staging (including endoscopic ultrasound) is important; stage IIE tumours and above do not usually respond to $H$ pylori treatment. (other than debilitating total gastrectomy) appears illogical, and the good results from surgery in the literature are likely to represent the indolent nature of the disease. However, surgery still has an important role in dealing with local complications

\section{PREDICTION OF THE TREATMENT RESPONSE TO HELICOBACTER PYLORI ERADICATION}

A major challenge is predicting which patients will comprise the $70 \%$ who respond to $H$ pylori treatment and, just as importantly, which patients will not respond and so should be offered radiotherapy or chemotherapy at an early stage.

\section{Histopathology}

The value of several histological and immunophenotypic features in the prediction of the treatment responses to $H$ pylori eradication has been examined. Increased numbers of transformed blasts, as expected, predicts poor responsiveness to $H$ pylori treatment. Immunohistochemical detection of expression of the costimulatory molecule CD86 is associated with lymphoma resolution following $H$ pylori eradication. ${ }^{47}$ However, it is not an accurate discriminator at the level of the individual patient.

\section{Endoscopic ultrasound}

The prognostic value of clinical staging has been extensively examined by endoscopic unltrasonography, which allows assessment of the extent of tumour invasion into the gastric wall and involvement of regional lymph nodes (table 1). This modality has been shown to predict $H$ pylori treatment response with reasonable accuracy, although some problems remain. In general, lymphomas of stage $\mathrm{II}_{\mathrm{E}}$ or above do not respond to $H$ pylori eradication. ${ }^{4-51}$ However, the prognostic value of staging in stage $\mathrm{I}_{\mathrm{E}}$ cases is limited although tumours that involve the muscularis propria or serosa (stage $\mathrm{I}_{\mathrm{E} 2}$ ) show a higher failure rate than those restricted to the submucosa (stage $\left.\mathrm{I}_{\mathrm{E} 1}\right)^{48-50}$ Paradoxically, the majority of gastric MALT lymphomas at diagnosis are at stage $\mathrm{I}_{\mathrm{E}}$ and approximately $20 \%$ of these cases will not respond to $H$ pylori eradication.

\section{MOLECULAR TESTING AND ITS UTILITY IN PREDICTING H PYLORI ERADICATION RESPONSE AND OTHER ASPECTS OF TUMOUR BEHAVIOUR}

Genetic abnormalities are common in gastric MALT lymphomas, and a wide range of such abnormalities have been described. One particular abnormality which is well characterised in haematological malignancies is that of chromosomal translocation and there have been major recent advances in characterisation of chromosome translocations

Table 1 Staging system for primary gastric lymphoma (modified Ann Arbor system) (from Radaszkiewicz 1992)*

\begin{tabular}{ll}
\hline$I_{E}$ & Localised disease-no lymph node involvement \\
$I_{E 1}$ & Confined to mucosa and submucosa \\
$I_{E 2}$ & Extending beyond the submucosa (into muscularis propria) \\
$\|_{E}$ & $\begin{array}{l}\text { Localised disease with lymph node involvement } \\
\|_{E 1}\end{array}$ \\
$\|_{E 2}$ & $\begin{array}{l}\text { Regional lymph nodes involved } \\
\text { Intration of lymph nodes beyond regional area }\end{array}$ \\
$I_{E}$ & $\begin{array}{l}\text { Localised disease but with lymph nodes involved on both sides } \\
\text { of diaphragm }\end{array}$ \\
$I_{E}$ & Diffuse or disseminate involvement of non-Gl tract organs
\end{tabular}

*Radaszkiewicz T, Dragosics B, Bauer P. Gastrointestinal malignant"Radaszkiewicz T, Dragosics B, Baver P. Gastrointestinal malignant-
lymphomas of the mucosa-associated lymphoid tissue-factors Relevant to prognosis. Gastroenterology 1992;105:1628-38. 
associated with MALT lymphomas. In chromosomal translocations, two chromosomes break and one is fused onto another. Most cells in which this occurs either have no selective advantage or are non-viable. However, in some cases, parts of two genes are fused together to make a new gene (fusion) which encodes a new protein (fusion product). In other cases, a gene is placed under the transcriptional control of another gene, which deregulates its expression, often resulting in constitutive overexpression. If these changes confer a selective advantage in the niche in which the cell finds itself, the cells may grow, divide, and outcompete other cells. This is common in lymphomas. Chromosomal translocations give fascinating insights into the pathogenesis of lymphomas, and into oncogenic signalling in general. From the clinician's point of view, they may be important if they inform on natural history and treatment response. In the case of gastric MALT lymphoma, they are a good predictor of the response to $H$ pylori eradication, particularly when combined with endoscopic ultrasound. They also inform on prognosis and tumour behaviour.

\section{$T(11 ; 18)(Q 21 ; Q 21)$}

$\mathrm{t}(11 ; 18)$ means translocation of part of chromosome 11 onto chromosome 18 and vice versa. $(\mathrm{q} 21 ; \mathrm{q} 21)$ means that the breakpoints are in band 21 of the long " $\mathrm{q}$ " arm (rather than the short " $\mathrm{p}$ " arm) of both chromosomes. This is by far the most common translocation, occurring in approximately $25 \%$ of gastric MALT lymphomas.

\section{Background and mechanisms}

$\mathrm{t}(11 ; 18)$ causes reciprocal fusion of the API2 and MALT1 genes and generates an API2-MALT1 fusion product (fig 1). ${ }^{51-53}$ In its natural form, API2 inhibits the biological activity of proteins involved in apoptosis or programmed cell deathcaspases 3, 7, and 9. MALT1 is involved in antigen receptor mediated activation of a protein called nuclear factor $\kappa \mathrm{B}$ $(\mathrm{NF \kappa B})$, which is a major transcriptional regulator-that is, it controls expression of many genes in the cell. ${ }^{54}{ }^{55}$ API2-MALTI fusions are always "in frame". This means that they make a protein product comprising the first part of AP12 and the second part of MALT-1 rather than a nonsense protein. Neither the wild-type API2 nor the wild-type MALTl alone is capable of activating NFKB, but the API2-MALTl fusion product is a potent $\mathrm{NF \kappa B}$ activator. ${ }^{56}{ }^{57} \mathrm{NF} \kappa \mathrm{B}$ transactivates genes encoding such things as cytokines, growth factors, and apoptosis inhibitors-factors that are important for cellular activation, proliferation, and survival and may thus contribute to tumour development. In line with this, in vitro studies show that the API2-MALT1 fusion product protects cells from both p53 and FAS induced apoptosis and this protective effect depends on its ability to activate NFKB. ${ }^{58} 59$

\section{Practical diagnosis and behaviour}

$\mathrm{t}(11 ; 18)$ can be detected fairly simply by reverse transcription-PCR (RT-PCR) amplification of the API2-MALT1 fusion mRNA transcript or by interphase fluorescence in situ hybridisation (FISH). Both of these techniques can routinely be applied to formalin fixed paraffin embedded tissue biopsies (fig 2). ${ }^{60}{ }^{61}$ Extensive screening for $t(11 ; 18)$ using these methods shows that the translocation is specifically associated with MALT lymphoma-it has not been found in other non-Hodgkin lymphomas or in inflammatory disorders that predispose to or coexist with lymphoma, such as $H$ pylori associated gastritis. ${ }^{62-66}$ The translocation occurs at variable frequencies in MALT lymphoma of different sites, from $0 \%$ in those from the thyroid and skin to $40 \%$ in those from the lung. ${ }^{62-68}$ In gastric MALT lymphoma, $\mathrm{t}(11 ; 18)$ is detected in $30 \%$ of cases and is more common in cases that show spread to regional lymph nodes or distal sites. ${ }^{67}$ However, despite $t(11 ; 18):$ AP12
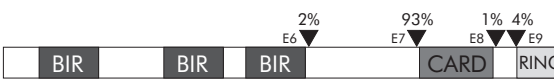

MALT 1

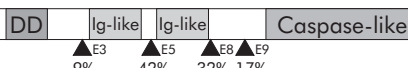

Known breakpoints and their frequency are indicated by arrowheads.

BIR, baculovirus IAP repeat; CARD, caspase recruitment domain; DD, death domain.

This translocation results in a break in each gene, and formation of a fusion consisting of the first part of $A P 12$ and the second part of MALT1.

The AP12-MALT1 fusion product activates NFKB

\section{$t(1 ; 14): \quad$ BCL10}

This translocation juxtaposes the BCL10 gene to the $\lg$ locus and causes strong BCL10 nuclear expression

$\mathrm{BCL} 10$ activates $\mathrm{NFKB}$

$\dagger(14 ; 18):$ MALT1 DD $\quad$ |g-like $\mid \lg$-lik Caspase-like

This translocation juxtaposes the MALT1 gene to the $\lg$ locus and causes strong MALT1 expression In the presence of BCL10, MALT1 activates NFKB

$t(3 ; 14)$ :

\begin{tabular}{l|l|l|l|l|l|l|l|} 
FOXP1 & Glutamine rich & & ZF & LZ & & Winged helix & \\
\hline \multicolumn{7}{c}{ ZF Zinc finger } \\
\cline { 2 - 5 }
\end{tabular}

This juxtaposes the FOXP1 gene to the Ig locus and deregulates its expression FOXP1 likely acts as a transcriptional repressor, but the mechanism underlying its oncogenic activity is unknown
Figure 1 Key features of mucosa associated lymphoid tissue (MALT) lymphoma associated chromosomal translocations. 


\section{RT-PCR of the API2-MALT1}

fusion transcripts

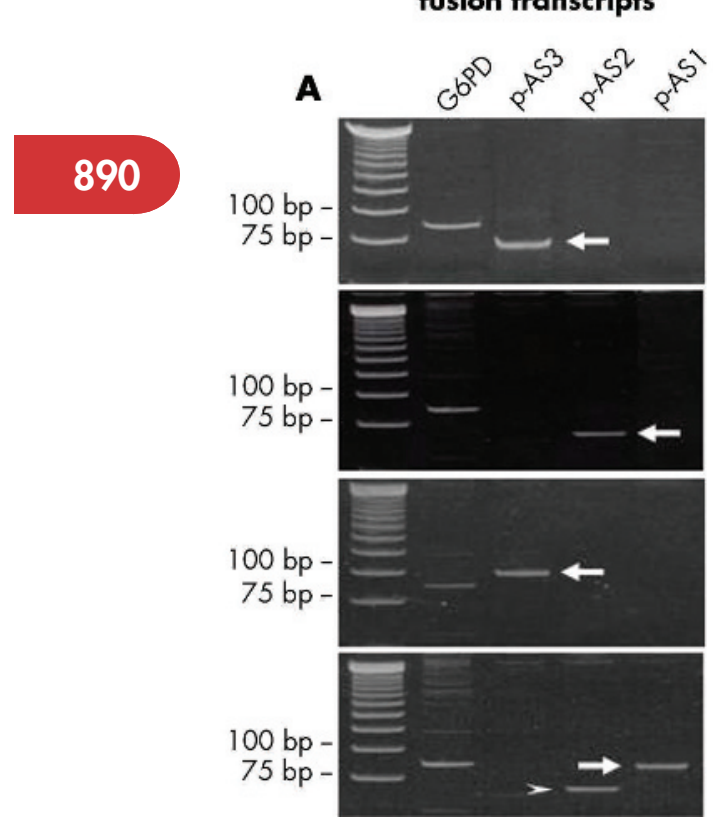

Interphase FISH with API2/MALT 1 dual-colour dual fusion probes

B

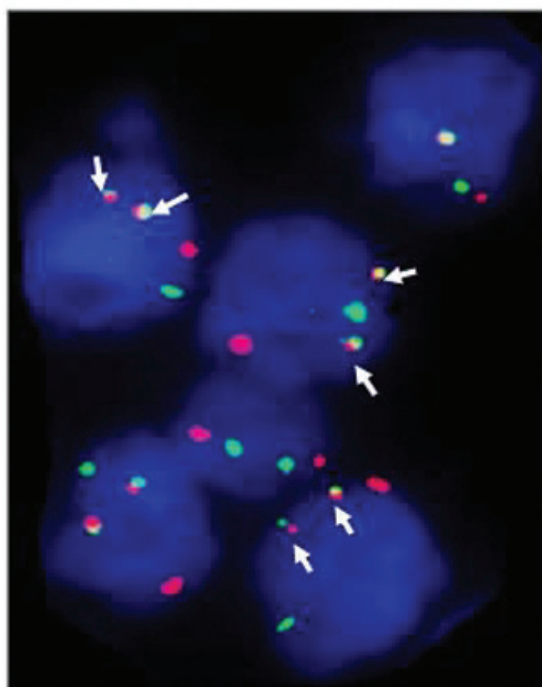

Figure 2 Detection of $t(11 ; 18)(q 21 ; q 21)$. (A) Four examples of products of reverse transcription polymerase chain reaction of the API2MALT1 fusion from formalin fixed paraffin embedded tissues, run on an agarose gel. The left lane is the size ladder. G6PD serves as a control for RNA quality. P-AS3, 2, and 1 are different primer sets designed to amplify DNA across various possible AP12MALT-1 fusion positions. The bold arrows point to the main amplified AP12-MALT1 fusion product. The small arrowhead shows an alternative splicing variant of the API2-MALT1 transcript in example 4. (B) Example of interphase fluorescence in situ hybridisation (FISH) with API2/MALT1 dual colour, dual fusion translocation probes. Arrowheads indicate colocalisation of the red (MALT1) and green (API2) signals. this significant association of $t(11 ; 18)$ with advanced cases, the translocation positive MALT lymphomas rarely if ever undergo high grade transformation.

\section{Response to $\boldsymbol{H}$ pylori treatment}

Liu et al retrospectively examined the value of $t(11 ; 18)$ in predicting the response of gastric MALT lymphoma to $H$ pylori eradication. ${ }^{60}$ Among the 111 cases of gastric MALT lymphoma examined, $\mathrm{t}(11 ; 18)$ was present in $42 / 63(67 \%)$ nonresponsive cases, including $26 / 43(60 \%)$ at stage $\mathrm{I}_{\mathrm{E}}$. In contrast, translocation was detected in only $2 / 48$ responsive cases. Interestingly, the two translocation positive responsive cases showed only a temporary response to $H$ pylori eradication and relapsed without $H$ pylori reinfection. ${ }^{60} 69$ Several independent studies have reported similar findings. ${ }^{66} 7071$ Thus in summary, $\mathrm{t}(11 ; 18)$ positive cases rarely if ever respond to $H$ pylori treatment; for $t(11 ; 18)$ negative cases, approximately $75 \%$ of cases, maybe more, respond.

\section{$\mathrm{T}(1 ; 14)(\mathrm{P} 22 ; \mathrm{Q} 32) / \mathrm{T}(1 ; 2)(\mathrm{P} 22 ; \mathrm{Q} 12)$}

This is a translocation from the short arm of chromosome 1 to the long arm of chromosome 14 and vice versa, or a

\section{$f(11 ; 18)(q 21 ; q 21)$}

- $t(1,18)$ is the most common stable chromosomal translocation in gastric MALT lymphomas, occurring in approximately $30 \%$.

$t(11 ; 18)$ tumours are locally aggressive but rarely if ever transform into DLBCL.

- $(11 ; 18)$ tumours rarely if ever show a sustained response to $H$ pylori treatment.

- The $t(11 ; 18)$ translocation can be detected by standard methodologies available in most clinical reference laboratories.

- Other translocations provide interesting insights into tumour biology and cell signalling but their clinical consequences require further research. translocation from the short arm of chromosome 1 to the long arm of chromosome 2 and vice versa. It occurs in approximately $5 \%$ of gastric MALT lymphomas.

\section{Background and mechanisms}

$\mathrm{t}(1 ; 14) / \mathrm{t}(1 ; 2)$ does not form a fusion of genes but instead brings the entire $B C L 10$ gene under the regulatory control of the Ig heavy or light chain gene, leading to uncontrolled $B C L 10$ expression (fig 1). ${ }^{72-74}$ Studies of BCL10 knockout mice show that the natural function of BCL10 is to link antigen receptor signalling to the $\mathrm{NF \kappa B}$ pathway. ${ }^{75}{ }^{76}$ In response to surface antigen receptor stimulation, BCL10 oligomerises and binds MALTl, which subsequently triggers the molecular events leading to NFKB activation. ${ }^{77}$ In MALT lymphoma with $\mathrm{t}(1 ; 14)$ or variants, upregulated BCL10 production leads to aberrant NFKB activation, ${ }^{78}$ and this has been shown to prevent $\mathrm{B}$ cell receptor induced growth arrest and apoptosis. ${ }^{79}$

In line with the physiological role of BCL10, the protein is usually expressed predominantly in the cytoplasm of normal B cells. ${ }^{80}$ Intriguingly, BCL10 is strongly expressed in the nuclei of MALT lymphoma cells with $t(1 ; 14)$ or variant (fig 3 ). ${ }^{80} \mathrm{~A}$ moderate nuclear BCL10 expression is also seen in up to $50 \%$ of $\mathrm{t}(1 ; 14)$ negative cases, including almost all $\mathrm{t}(11 ; 18)$ positive cases and up to $20 \%$ of cases without $\mathrm{t}(11 ; 18) .{ }^{6768} 81$ These observations strongly suggest that nuclear BCL10 may confer additional oncogenic activity yet to be identified.

\section{Practical diagnosis, behaviour, and response to $H$ pylori treatment}

$\mathrm{t}(1 ; 14)$ and its variant can be screened for by BCL10 immunohistochemistry to identify those with strong nuclear BCL10 expression, followed by confirmation with interphase FISH (fig 3). ${ }^{68} t(1 ; 14)$ and its variant are specifically associated with MALT lymphoma and not with other lymphoma subtypes. ${ }^{68}$ They are primarily seen in MALT lymphoma from the lung and stomach, and occur in approximately $5 \%$ of gastric MALT lymphomas. ${ }^{68} 82$ 
Tonsil germinal centre

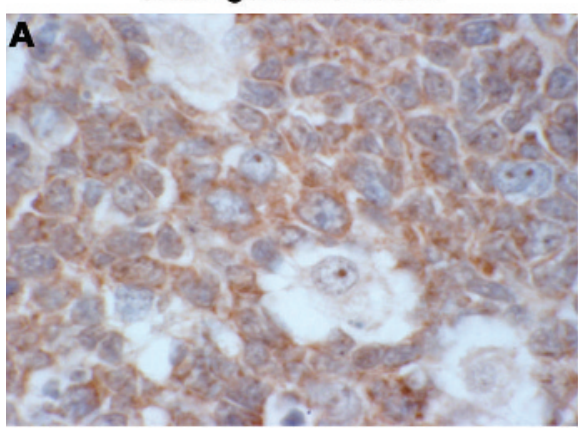

†(1;14)+ve MALT lymphoma

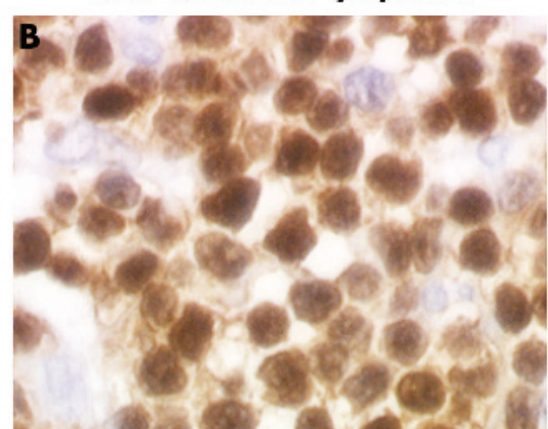

BCL10 break-apart probes

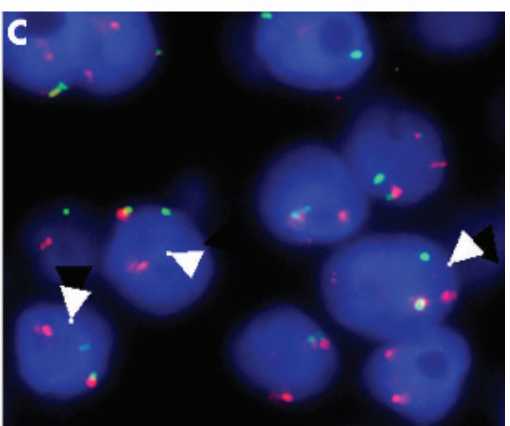

Figure 3 Detection of $t(1 ; 14)(p 22 ; q 32)$. BCL10 immunohistochemistry (brown) shows cytoplasmic staining in tonsil germinal centre B cells (A) but strong nuclear staining in mucosa associated lymphoid tissue (MALT) lymphoma cells with $t(1 ; 14)$ (B). (C) Interphase fluorescence in situ hybridisation with BCL10 dual colour break-apart probes in a case of MALT lymphoma with strong BCL10 nuclear staining. Break-apart probes are directed against regions either side of the putative chromosomal breakpoints $5^{\prime}$ to the BCL10 gene. Split of red and green signals (indicated by arrowheads) during interphase proves that there has been a chromosomal break in this region.

$\mathrm{t}(1 ; 14)$ positive gastric MALT lymphomas are typically of advanced stage. ${ }^{83}$ A preliminary study suggests that gastric MALT lymphomas with strong BCL10 nuclear expression or $\mathrm{t}(1 ; 14)$ do not respond to $H$ pylori eradication. ${ }^{83}$

\section{$T(14 ; 18)(Q 32 ; Q 21)$}

$\mathrm{t}(14 ; 18)(\mathrm{q} 32 ; \mathrm{q} 21)$ brings the MALT1 gene to the Ig heavy chain locus, deregulating its expression (fig 1). ${ }^{84}{ }^{85}$ MALT1 requires $\mathrm{BCL10}$ to activate $\mathrm{NF \kappa B},{ }^{5657}$ and high levels of cytoplasmic expression of both MALT1 and BCL10 are found in tumour cells with $t(14 ; 18) .{ }^{86}$ Translocation can be screened by MALT1 and BCL10 immunohistochemistry followed by interphase FISH. ${ }^{86}$ Studies so far indicate that the translocation occurs frequently in MALT lymphoma of the lung and ocular adnexae but rarely in those from the stomach. ${ }^{82}$ 86-88 The clinical significance of $\mathrm{t}(14 ; 18)$ in gastric MALT lymphoma is unknown

\section{$\mathrm{T}(3 ; 14)(\mathrm{P} 14 ; \mathrm{Q} 32)$}

$\mathrm{t}(3 ; 14)(\mathrm{pl} 14 ; \mathrm{q} 32)$ brings the FOXP1 gene to the Ig heavy chain locus and deregulates its expression (fig 1). ${ }^{89} 90$ FOXPl is a member of the family of forkhead/winged-helix transcription factors and is believed to be a transcriptional repressor based on its protein structure-that is, it is believed to switch genes off or downregulate them. The functions of FOXP1 in normal $\mathrm{B}$ and $\mathrm{T}$ cell biology and its role in MALT lymphoma pathogenesis are unknown. Translocation can be detected by interphase FISH. Studies so far show that FOXPI involving chromosomal translocation is frequently seen in MALT lymphomas of the thyroid, ocular adnexa, and skin, but rarely in those from the stomach. ${ }^{89} 90$ Unlike the other three MALT lymphoma chromosomal translocations discussed above, $\mathrm{t}(3 ; 14)$ is not specific to MALT lymphoma, having been found in DLBCL and B cell non-Hodgkin's lymphoma, not otherwise specified..$^{90}$ The clinical significance of FOXP1involving translocations is unknown.

\section{CONCLUSIONS}

Recent molecular advances into gastric MALT lymphoma have provided insights into its pathogenesis and have potential implications for its management. Accurate prediction of which tumours will respond to $H$ pylori eradication should allow early recourse to further treatment-low dose radiotherapy or chemotherapy. Endoscopic ultrasound is an

\section{Summary points}

- Low grade gastric MALT lymphoma is usually caused by $H$ pylori infection.

- It is an indolent disease but may become locally aggressive, spread, or undergo high grade transformation.

- Treatment of the infection cures the disease in approximately $70 \%$ of cases.

- Resistant or non-localised disease is treated with low dose radiotherapy or single agent chemotherapy; surgery is now used only for complications.

- Accurate staging requires endoscopic ultrasound; most tumours of stage $\|_{E}$ or above do not respond to $H$ pylori treatment.

- Molecular testing for chromosomal translocations is now simple and informative.

- $t(1 ; 18)$ tumours $(\sim 25 \%$ of total) rarely if ever respond to $H$ pylori treatment, are locally aggressive, but rarely undergo high grade transformation.

- Other translocations are less common and their clinical utility is still unclear.

- Radiotherapy or chemotherapy should be considered early in stage $\|_{E}$ disease and for all $t(11 ; 18)$ tumours.

important staging tool, and tumours of stage $\mathrm{II}_{\mathrm{E}}$ and above rarely respond to $H$ pylori treatment alone. Screening for $\mathrm{t}(11 ; 18)$ has most potential utility in stage $\mathrm{I}_{\mathrm{E}}$ tumours: those found to be positive will almost invariably need further treatment, usually low dose radiotherapy. However, even in these tumours, $H$ pylori is usually sought and eradicated. This is done for two reasons. Firstly, there are reports of occasional $\mathrm{t}(11 ; 18)$ positive lymphomas responding to $H$ pylori treatment. Secondly, there is a perception that $H$ pylori treatment may reduce the risk of further de novo tumours arising, either lymphomas or gastric adenocarcinomas (which occur not uncommonly in these patients). However, hard evidence showing that $H$ pylori eradication has the benefit of secondary prevention in this setting is lacking. In $t(11 ; 18)$ negative cases, $H$ pylori treatment alone will often lead to complete regression, or regression to the stage of minimal residual disease, which current research suggests may be equivalent to a cure. However, a few $t(11 ; 18)$ negative cases will not respond or will show an incomplete response, so these patients need careful endoscopic follow up and treatment 
with radiotherapy or chemotherapy if necessary. Screening for translocations other than $t(11 ; 18)$ is still of unproven benefit and should remain a topic for further research. Further research is also needed to define more carefully the role of $t(11 ; 18)$ screening in clinical management.

\section{ACKNOWLEDGEMENTS}

Professor Du's work is supported by research grants from the Leukaemia Research Fund UK, Leukaemia, Association for International Cancer Research and Leukaemia and Lymphoma Society USA. Professor Atherton's work is supported by Cancer Research UK, CORE, the Medical Research Council, and the University of Nottingham.

\section{Authors' affiliations}

M-Q Du, Division of Molecular Histopathology, Department of Pathology, University of Cambridge, Addenbrooke's Hospital, Cambridge, UK

J C Atherton, Wolfson Digestive Diseases Centre, University Hospital, Nottingham, UK

\section{REFERENCES}

1 Wotherspoon AC, Doglioni C, Diss TC, et al. Regression of primary low-grade B-cell gastric lymphoma of mucosa-associated lymphoid tissue type after eradication of Helicobacter pylori. Lancet 1993;342:575-7.

2 Isaacson P, Wright DH. Malignant lymphoma of mucosa-associated lymphoid tissue. A distinctive type of B-cell lymphoma. Cancer 1983;52:1410-6.

3 Isaacson PG, Wright DH, Ralfkiaer E, et al. Enteropathy-type T-cell lymphoma. In: Jaffe ES, Harris NL, Stein H, et al. World Health Organisation Classification of tumours: pathology and genetics, tumours of haematopaoitic and lymphoid tissues. Lyon: IARC, 2001:208-9.

4 Wotherspoon AC, Ortiz-Hidalgo C, Falzon MR, et al. Helicobacter pylori gastritis and primary B cell gastric lymphoma. Lancet 1991;338:1 175-6.

5 Hummel M, Oeschger S, Barth TFE, et al. Wotherspoon criteria combined with $B$ cell clonality analysis by advanced PCR technology discriminates cryptic gastric marginal zone lymphoma from chronic gastritis. Gut 2006;55:782-7.

6 Wotherspoon AC, Doglioni C, Isaacson PG. Low-grade gastric B-cell lymphoma of mucosa-associated lymphoid tissue (MALT): a multifocal disease. Histopathology 1992;20:29-34.

7 Du MQ, Diss TC, Dogan A, et al. Clone-specific PCR reveals wide dissemination of gastric MALT lymphoma to the gastric mucosa. J Pathol 2000; 192:488-93.

8 Hoshida Y, Kusakabe H, Furukawa H, et al. Reassessment of gastric lymphoma in light of the concept of mucosa-associated lymphoid tissue lymphoma: analysis of 53 patients. Cancer 1997;80:1151-9.

9 Chang DK, Chin YJ, Kim JS, et al. Lymph node involvement rate in low-grade gastric mucosa-associated lymphoid tissue lymphoma - too high to be neglected. Hepatogastroenterology 1999;46:2694-700.

$10 \mathrm{Ko} \mathrm{YH,} \mathrm{Han} \mathrm{JJ,} \mathrm{Noh} \mathrm{JH,} \mathrm{et} \mathrm{al.} \mathrm{Lymph} \mathrm{nodes} \mathrm{in} \mathrm{gastric} \mathrm{B-cell} \mathrm{lymphoma:} \mathrm{pattern}$ of involvement and early histological changes. Histopathology 2002:40:497-504

11 Du MQ, Xu CF, Diss TC, et al. Intestinal dissemination of gastric mucosa associated lymphoid tissue lymphoma. Blood 1996;88:4445-51.

12 Du $M Q$, Peng HZ, Dogan A, et al. Preferential dissemination of B-cell gastric mucosa-associated lymphoid tissue (MALT) lymphoma to the splenic marginal zone. Blood 1997;90:4071-7.

13 Thieblemont C, Berger F, Dumontet C, et al. Mucosa-associated lymphoid tissue lymphoma is a disseminated disease in one third of 158 patients analyzed. Blood 2000;95:802-6.

14 Dogan A, Du M, Koulis A, et al. Expression of lymphocyte homing receptors and vascular addressins in low-grade gastric B-cell lymphomas of mucosaassociated lymphoid tissue. Am J Pathol 1997;151:1361-9.

15 Raderer M, Vorbeck F, Formanek M, et al. Importance of extensive staging in patients with mucosa-associated lymphoid tissue (MALT)-type lymphoma. Br J Cancer 2000;83:454-7.

16 Jaffe ES, Harris NL, Stein H, et al. Patology and genetics of tumours of haematopietic and lymphoid tissues. World Health OrganisationClassification of tumours. Lyon: IARC Press, 2001.

17 Chan JK, Ng CS, Isaacson PG. Relationship between high-grade lymphoma and low-grade B-cell mucosa-associated lymphoid tissue lymphoma (MALToma) of the stomach. Am J Pathol 1990;136:1153-64.

18 Peng H, Du M, Diss TC, et al. Genetic evidence for a clonal link between low and high-grade components in gastric MALT B-cell lymphoma. Histopathology 1997:30:425-9.

19 Matolcsy A, Nagy M, Kisfaludy N, et al. Distinct clonal origin of low-grade MALT-type and high-grade lesions of a multifocal gastric lymphoma. Histopathology 1999;34:6-8.

20 Cogliatti SB, Schmid U, Schumacher U, et al. Primary B-cell gastric lymphoma: a clinicopathological study of 145 patients. Gastroenterology 1991;101:1159-70.
21 Wotherspoon AC, Ortiz Hidalgo C, Falzon MR, et al. Helicobacter pyloriassociated gastritis and primary B-cell gastric lymphoma. Lancet 1991;338:1175-6.

22 Nakamura S, Yao T, Aoyagi K, et al. Helicobacter pylori and primary gastric lymphoma. A histopathologic and immunohistochemical analysis of 237 patients. Cancer 1997;79:3-11.

23 Hussell T, Isaacson PG, Crabtree JE, et al. The response of cells from lowgrade B-cell gastric lymphomas of mucosa-associated lymphoid tissue to Helicobacter pylori. Lancet 1993;342:571-4.

24 Hussell T, Isaacson PG, Crabtree JE, et al. Helicobacter pylori-specific tumourinfiltrating T cells provide contact dependent help for the growth of malignant $\mathrm{B}$ cells in low-grade gastric lymphoma of mucosa-associated lymphoid tissue. J Pathol 1996;178:122-7.

25 D'Elios MM, Amedei A, Manghetti M, et al. Impaired T-cell regulation of B-cell growth in Helicobacter pylori-related gastric low-grade MALT lymphoma. Gastroenterology 1999;117:1105-12.

26 Du MQ, Isaccson PG. Gastric MALT lymphoma: from aetiology to treatment Lancet Oncol 2002:3:97-104.

27 Morgner A, Lehn N, Andersen LP, et al. Helicobacter heilmannii-associated primary gastric low-grade MALT lymphoma: complete remission after curing the infection. Gastroenterology 2000;1 18:821-8.

28 Wundisch T, Neubauer A, Stolte M, et al. B-cell monoclonality is associated with lymphoid follicles in gastritis. Am J Surg Pathol 2003;27:882-7.

29 Fischbach WF, Goebeler-Kolve MF, Starostik PF, et al. Minimal residual low grade gastric MALT-type lymphoma after eradication of Helicobacter pylori. Lancet 2002;360:547-8.

30 Goebeler-Kolve ME, Savio A, Wuenchsch T, et al. Patients with minimal residuals of gastric MALT lymphoma after erafication of $\mathrm{H}$-pylori do no need any oncological treatment! Experiences from a larger international series. Gastroentorology 2005; 128:A289-90.

31 Malfertheiner PF, Megraud FF, O'Morain CF, et al. Current concepts in the management of Helicobacter pylori infection-the Maastricht 2-2000 Consensus Report. Aliment Pharmacol Ther 2002;16:167-80.

32 Ford AF, Moayyedi P. How can the current strategies for Helicobacter pylor eradication therapy be improved? Can J Gastroenterol 2003;17/suppl B):36-40B.

33 Fischbach WF, Goebeler-Kolve ME, Dragosics BF, et al. Long term outcome of patients with gastric marginal zone B cell lymphoma of mucosa associated ymphoid tissue (MALT) following exclusive Helicobacter pylori eradication therapy: experience from a large prospective series. Gut 2004;53:34-7.

34 Cavalli F, Isaacson PG, Gascoyne RD, et al. MALT lymphomas. Hematology (Am Soc Hematol Educ Program) 2001:241-58.

35 Levy MF, Copie-Bergman CF, Traulle CF, et al. Conservative treatment of primary gastric low-grade B-cell lymphoma of mucosa-associated lymphoid tissue: predictive factors of response and outcome. Am J Gastroenterol 2002;97:292-7.

36 Du $M Q$, Isaccson P, Isaccson PG. Gastric MALT lymphoma: from aetiology to treatment. Lancet Oncol 2002;3:97-104

37 Caletti GF, Zinzani PL FAU, Fusaroli PF et al. The importance of endoscopic ultrasonography in the management of low-grade gastric mucosa-associated lymphoid tissue lymphoma. Aliment Pharmacol Ther 2002; 16:1715-22.

38 Stolte MF, Bayerdorffer E, Morgner AF, et al. Helicobacter and gastric MALT lymphoma. Gut 2002;50(suppl 3):11119-24.

39 Ahmad AF, Govil YF, Frank BB. Gastric mucosa-associated lymphoid tissue lymphoma. Am J Gastroenterol 2003;98:975-86.

40 Hammel PF, Haioun CF, Chaumette MT, et al. Efficacy of single-agent chemotherapy in low-grade B-cell mucosa-associated lymphoid tissue lymphoma with prominent gastric expression. J Clin Oncol 1995;13:2524-9.

41 Zucca E, Bertoni FF, Roggero E, et al. The gastric marginal zone B-cell lymphoma of MALT type. Blood 2000;96:410-19.

42 Schechter NR, Yahalom J. Low-grade MALT lymphoma of the stomach: a review of treatment options. Int J Radiat Oncol Biol Phys 2000:46:1093-103.

43 Martinelli GF, Laszlo DF, Ferreri AJ, et al. Clinical activity of rituximab in gastric marginal zone non-Hodgkin's lymphoma resistant to or not eligible for anti-Helicobacter pylori therapy. J Clin Oncol 2005;23:1979-83.

44 Tsang RW, Gospodarowicz M, Gospodarowicz MK, et al. Localized mucosaassociated lymphoid tissue lymphoma treated with radiation therapy has excellent clinical outcome. J Clin Oncol 2003;21:4157-64.

45 Schmelz R, Thiede C, Dawel $M$, et al. Helyx study part $i$ and ii: treatment of low-grade gastric non-Hodgkin's lymphoma of mucosa-associated lymphoid tissue (MALT) type stages I and II, an interim analysis. Gastroentorology 2005; 128(Suppl 2):A295.

46 Aviles A, Nambo MJ, Neri N, et al. Mucosa-associated lymphoid tissue (MALT) lymphoma of the stomach: results of a controlled clinical trial. Med Oncol 2005:22:57-62.

47 de Jong D, Vyth-Dreese F, Dellemijn T, et al. Histological and immunological parameters to predict treatment outcome of Helicobacter pylori eradication in low-grade gastric MALT lymphoma. J Pathol 2001;193:318-24.

48 Sackmann M, Morgner A, Rudolph B, et al. Regression of gastric MALT lymphoma after eradication of Helicobacter pylori is predicted by endosonographic staging. MALT Lymphoma Study Group. Gastroenterology 1997;113:1087-90.

49 Ruskone-Fourmestraux A, Lavergne A, Aegerter PH, et al. Predictive factors for regression of gastric MALT lymphoma after anti-Helicobacter pylori treatment. Gut 2001;48:297-303.

50 Nakamura S, Matsumoto T, Suekane H, et al. Predictive value of endoscopic ultrasonography for regression of gastric low grade and high grade MALT lymphomas after eradication of Helicobacter pylori. Gut 2001;48:454-60.

51 Akagi T, Motegi M, Tamura A, et al. A novel gene, MALT1 at 18q21, is involved in $\mathrm{t}(11 ; 18)$ (q21; $\mathrm{q} 21$ ) found in low-grade B-cell lymphoma of mucosa-associated lymphoid tissue. Oncogene 1999;18:5785-94. 
52 Dierlamm J, Baens M, Wlodarska I, et al. The apoptosis inhibitor gene API2 and a novel $18 \mathrm{q}$ gene, MLT, are recurrently rearranged in the $t(11 ; 18)(q 21 ; q 21)$ associated with mucosa-associated lymphoid tissue lymphomas. Blood 1999;93:3601-9.

53 Morgan JA, Yin Y, Borowsky AD, et al. Breakpoints of the $+(11 ; 18)(q 21 ; q 21)$ in mucosa-associated lymphoid tissue (MALT) lymphoma lie within or near the previously undescribed gene MALT1 in chromosome 18. Cancer Res 1999;59:6205-13.

54 Ruland J, Duncan GS, Wakeham A, et al. Differential requirement for Malt1 in T and B cell antigen receptor signaling. Immunity 2003:19:749-58.

55 Ruefli-Brasse AA, French DM, Dixit VM. Regulation of NF-kappaB-dependent lymphocyte activation and development by paracaspase. Science 2003;302:1581-4.

56 Uren GA, O'Rourke K, Aravind L, et al. Identification of paracaspases and metacaspases: two ancient families of caspase-like proteins, one of which plays a key role in MALT lymphoma. Mol Cell 2000;6:961-7.

57 Lucas PC, Yonezumi M, Inohara N, et al. Bdl10 and MALT1, independent targets of chromosomal translocation in malt lymphoma, cooperate in a nove NF-kappa B signaling pathway. J Biol Chem 2001;276:19012-19.

58 Ho L, Davis RE, Conne B, et al. MALT1 and the API2-MALT1 fusion act between CD40 and IKK and confer NF-kappa B-dependent proliferative advantage and resistance against FAS-induced cell death in B cells. Blood 2005; 105:2891-9

59 Stoffel A, Levine AJ. Actration of NF-kappaB by the API2/MALT1 fusions inhibits p53 dependant but not FAS induced apoptosis: a directional link between NF-kappaB and p53. Cell Cycle 2004;3:1017-20.

60 Liu $\mathrm{H}, \mathrm{Ye} \mathrm{H}$, Ruskone-Fourmestraux A, et al. $\mathrm{T}(11 ; 18)$ is a marker for all stage gastric MALT lymphomas that will not respond to $\mathrm{H}$. pylori eradication. Gastroenterology 2002;122:1286-94.

61 Dierlamm J, Baens M, Stefanova-Ouzounova M, et al. Detection of $\mathrm{t}(11 ; 18)(\mathrm{q} 21 ; \mathrm{q} 21)$ by interphase fluorescence in situ hybridization using API2 and MLT specific probes. Blood 2000;96:2215-18.

62 Remstein ED, James CD, Kurtin PJ. Incidence and subtype specificity of API2MALTI fusion translocations in extranodal, nodal, and splenic marginal zone lymphomas. Am J Pathol 2000;156:1183-8.

63 Baens M, Maes B, Steyls A, et al. The product of the $t(11 ; 18)$, an API2-MLT fusion, marks nearly half of gastric MALT type lymphomas without large cell proliferation. Am J Pathol 2000;156:1433-9.

64 Motegi M, Yonezumi M, Suzuki H, et al. API2-MALT1 chimeric transcripts involved in mucosa-associated lymphoid tissue type lymphoma predict heterogeneous products. Am J Pathol 2000;156:807-12.

65 Kalla J, Stilgenbaver S, Schaffner C, et al. Heterogeneity of the API2-MALT1 gene rearrangement in MALT-type lymphoma. Leukemia 2000;14:1967-74.

66 Nakamura T, Nakamura S, Yonezumi M, et al. Helicobacter pylori and the $\mathrm{t}(11 ; 18)(\mathrm{q} 21 ; \mathrm{q} 21)$ translocation in gastric low-grade B-cell lymphoma of mucosa-associated lymphoid tissue type. Jpn J Cancer Res 2000;91:301-9.

67 Liu H, Ye H, Dogan A, et al. T(11;18)(q21;q21) is associated with advanced mucosa-associated lymphoid tissue lymphoma that expresses nuclear BCL10. Blood 2001;98:1182-7.

$68 \mathrm{Ye} \mathrm{H}$, Liu H, Attygalle A, et al. Variable frequencies of $t(11 ; 18)(q 21 ; q 21)$ in MALT lymphomas of different sites: significant association with CagA strains of $\mathrm{H}$ pylori in gastric MALT lymphoma. Blood 2003;102:1012-18.

69 Liu H, Ruskone Fourmestraux A, Lavergne-Slove A, et al. Resistance of $t(11 ; 18)$ positive gastric mucosa-associated lymphoid tissue lymphoma to Helicobacter pylori eradication therapy. Lancet 2000;357:39-40.

70 Alpen B, Neubauer A, Dierlamm J, et al. Translocation $t(11 ; 18)$ absent in early gastric marginal zone B-cell lymphoma of MALT type responding to eradication of Helicobacter pylori infection. Blood 2000;95:4014-15.

71 Yeh KH, Kuo SH, Chen LT, et al. Nuclear expression of BCL10 or nuclea factor kappa B helps predict Helicobacter pylori-independent status of low- grade gastric mucosa-associated lymphoid tissue lymphomas with or without $t(11 ; 18)(q 21 ; q 21)$. Blood 2005;106:1037-41.

72 Willis TG, Jadayel DM, Du MQ, et al. Bcl10 is involved in $\mathrm{t}(1 ; 14)(\mathrm{p} 22 ; \mathrm{q} 32)$ of MALT B cell lymphoma and mutated in multiple tumor types. Cell 1999:96:35-45.

73 Zhang $Q$, Siebert $R$, Yan $M$, et al. Inactivating mutations and overexpression of BCL10, a caspase recruitment domain-containing gene, in MALT lymphoma with $+(1 ; 14)(\mathrm{p} 22 ; \mathrm{q} 32)$. Nat Genet 1999;22:63-8.

74 Achuthan R, Bell SM, Leek JP, et al. Novel translocation of the BCL10 gene in a case of mucosa associated lymphoid tissue lymphoma. Genes Chromosomes Cancer 2000;29:347-9.

75 Ruland J, Duncan GS, Elia A, et al. Bcl10 is a positive regulator of antigen receptor-induced activation of NF-kappaB and neural tube closure. Cell $2001 ; 104: 33-42$

76 Xue L, Morris SW, Orihuela $C$, et al. Defective development and function of Bcl10-deficient follicular, marginal zone and B1 B cells. Nat Immunol 2003;4:857-65.

77 Thome M. CARMAI, BCL-10 and MALT1 in lymphocyte development and activation. Nat Rev Immunol 2004;4:348-59.

78 Isaacson PG, Du MQ. MALT lymphoma: from morphology to molecules. Nat Rev Cancer 2004;4:644-653.

79 Tian MT, Gonzalez G, Scheer B, et al. Bcl 10 can promote survival of antigenstimulated B lymphocytes. Blood 2005;106:2105-12.

$80 \mathrm{Ye} \mathrm{H}$, Dogan A, Karran L, et al. BCL10 expression in normal and neoplastic lymphoid tissue: nuclear localization in MALT lymphoma. Am J Pathol 2000; 157:1 1 147-54

81 Maes B, Demunter A, Peeters B, et al. BCL10 mutation does not represent an important pathogenic mechanism in gastric MALT-type lymphoma, and the presence of the API2-MLT fusion is associated with aberrant nuclear BCL10 expression. Blood 2002;99:1398-404.

82 Streubel B, Simonitsch-Klupp I, Mullauer L, et al. Variable frequencies of MALT lymphoma-associated genetic aberrations in MALT lymphomas of different sites. Leukemia 2004;18:1722-6.

$83 \mathrm{Ye} \mathrm{H}$, Gong L, Liu H, et al. Strong BCL10 nuclear expression identifies gastric MALT lymphomas that do not respond to $\mathrm{H}$ pylori eradication. Gut 2006;55:137-9.

84 Streubel B, Lamprecht A, Dierlamm J, et al. T(14;18)(q32;q21) involving IGH and MALT1 is a frequent chromosomal aberration in MALT lymphoma. Blood 2003;101:2335-9.

85 Sanchez-Izquierdo D, Buchonnet G, Siebert R, et al. MALT1 is deregulated by both chromosomal translocation and amplification in B-cell non-Hodgkin lymphoma. Blood 2003;101:4539-46.

86 Ye H, Gong L, Liu H, et al. MALT lymphoma with $+(14 ; 18)(q 32 ; q 21) / I G H$ MALT1 is characterized by strong cytoplasmic MALT1 and BCL10 expression. J Pathol 2005;205:293-301.

87 Murga Penas EM, Hinz K, Roser K, et al. Translocations $t(11 ; 18)(q 21 ; q 21)$ and $+(14 ; 18)(q 32 ; q 21)$ are the main chromosomal abnormalities involving MLT/MALT1 in MALT lymphomas. Leukemia 2003;17:2225-9.

88 Remstein ED, Kurtin PJ, Einerson RR, et al. Primary pulmonary MALT lymphomas show frequent and heterogeneous cytogenetic abnormalities, including aneuploidy and translocations involving API2 and MALT1 and IGH and MALT1. Leukemia 2004;18:156-60.

89 Streubel B, Vinatzer U, Lamprecht A, et al. T(3;14)(p14.1;q32) involving IGH and FOXP1 is a novel recurrent chromosomal aberration in MALT lymphoma. Leukemia 2005; 19:652-8.

90 Wlodarska I, Veyt E, De Paepe P, et al. FOXP1, a gene highly expressed in a subset of diffuse large B-cell lymphoma, is recurrently targeted by genomic aberrations. Leukemia 2005; 19:1299-305. 